\title{
PENERAPAN MODEL PEMBELAJARAN BERBASIS MASALAH UNTUK MENINGKATKAN KEAKTIFAN DAN HASIL BELAJAR ILMU BANGUNAN GEDUNG PADA SISWA KELAS $X$ TEKNIK KONSTRUKSI BATU DAN BETON SMK NEGERI 2 BINJAI TAHUN AJARAN 2014/2015
}

\author{
Andika Syahputra ${ }^{1}$, Darwin ${ }^{2}$ \\ ${ }^{1}$ Alumni Program Studi Pendidikan Teknik Bangunan, Fakultas Teknik UNIMED \\ ${ }^{2}$ Dosen Pengajar Jurusan Pendidikan Teknik Bangunan, Fakultas Teknik UNIMED \\ (Darwin.dbep@gmail.com)
}

\begin{abstract}
ABSTRAK
Penelitian ini bertujuan untuk meningkatkan keaktifan dan hasil belajar Ilmu Bangunan Gedung pada siswa kelas X di SMK N 2 Binjai dengan menerapakan pembelajaran Berbasis Masalah. Subjek penelitian ini adalah siswa kelas X Program Keahlian Teknik Konstruksi Batu dan Beton SMK N 2 Binjai Tahun Ajaran 2014/2015 berjumlah 31 orang, Hasil penelitian ini dilakukan pada siklus 1 keaktifan belajar siswa belum mengalami peningkatan, tetapi setelah dilakukan siklus 2 keaktifan belajar siswa meningkat. Pada siklus 1 nilai rata-rata keaktifan belajar siswa adalah $63 \%$ dengan kategori kurang aktif 4 orang (12,90\%), Cukup aktif 14 orang $(45,19 \%)$, Aktif 13 orang $(41,94 \%)$, dan sangat aktif tidak ada $(0 \%)$. Sedangkan pada siklus 2 keaktifan belajar siswa mengalami peningkatan yaitu dengan nilai rata-rata $81 \%$ dengan kategori Cukup aktif 4 orang $(12,90 \%)$, aktif 17 orang $(54,84 \%)$, dan sangat aktif 10 orang $(32,26 \%)$ dari nilai ideal 100. Rata-rata hasil belajar Ilmu Bangunan Gedung siswa setelah penerapan pembelajaran Berbasis Masalah mengalami peningkatan, dari siklus 1 nilai rata-rata hasil belajar Ilmu Bangunan Gedung siswa adalah 66,61\% yaitu siswa tidak tuntas sebanyak 12 orang $(38,71 \% \%)$ dan siswa yang tuntas sebayak 19 orang $(61,29 \%)$ dari nilai ideal 100 . Pada siklus 2 nilai rata-rata hasil belajar Ilmu bangunan gedung siswa meningkat menjadi $76,10 \%$ dengan siswa tidak tuntas 4 orang $(12,90 \%)$ dan siswa yang tuntas sebanyak 27 orang $(87,10 \% \%)$ dari nilai ideal 100. Dari data-data hasil penelitian disimpulkan bahwa keaktifan dan hasil belajar siswa meningkat dengan menerapkan pembelajaran Berbasis Masalah.
\end{abstract}

Kata Kunci : Pembelajaran Berbasis Masalah, Keaktifan, Hasil Belajar

\begin{abstract}
This research aims to enhance the activity and learning outcomes of Sciences Building in class X in SMK N 2 Binjai by applying the Problem Based Learning. The subjects were students of class X Expertise Program Stone and Concrete Construction Engineering SMK N 2 Binjai Academic Year 2014/2015 amounted to 31 people, results of this study conducted in cycle 1 students' learning activeness has not increased, but after 2 cycles of increased student learning activeness, In cycle 1 the average value of students' learning activeness is $63 \%$ with less active category 4 (12.90\%), Pretty active 14 (45.19\%), Active 13 (41.94\%), and very active no (0\%). While in the second cycle students' learning activeness has risen by an average value of $81 \%$ with active enough category $4(12.90 \%)$, active $17(54.84 \%)$, and very active 10 people $(32.26 \%)$ from the ideal value of 100 . The average score Building Science learning outcomes of students after the application of problem-based learning has increased, from cycle 1 the average value of Sciences Building learning outcomes of students is $66.61 \%$ that the students did not complete as many as 12 people ( $38.71 \% \%)$ and students who completed sebayak $19(61.29 \%)$ of the ideal value of 100. In cycle 2 the average value of building science learning outcomes of students increased to $76.10 \%$ with the student does not complete $4(12.90 \%)$ and students who completed as many as 27 people $(87.10 \% \%)$ of the ideal value of 100 . From the data results of the study concluded that the activity and increased student learning outcomes by implementing a Problem Based Learning
\end{abstract}




\section{Pendahuluan}

Mengajar adalah penciptaan Sistem lingkungan yang memungkinkan terjadinya proses belajar mengajar Sistem Lingkungan ini ini terdiri dari komponen-komponen yang saling mempengaruhi, yakni tujuan instruksional yang ingin dicapai, materi yang diajarkan, guru dan siswa yang harus memainkan peranan serta ada dalam hubungan sosial tertentu, jenis kegiatan yang dilakukan, serta sarana dan prasarana belajar-mengajar yang tersedia.

Setiap sistem lingkungan atau setiap peristiwa belajar-mengajar mempunyai "profil" yang unik, yang mengakibatkan tercapainya tujuan-tujuan belajar yang berbeda. Tujuan-tujuan belajar yang pencapaiannya diusahakan secara eksplisit dengan tindakan instruksional tertentu dinamakan instruksional effect, yang biasanya berbentuk pengetahuan dan ketrampilan. Sedangkan tujuan-tujuan yang merupakan hasil pengiring, yang tercapainya karena siswa "menghidupi" suatu sistem lingkungan belajar tertentu, seperti kemampuan berfikir kritis dan kreatif atau sikap terbuka menerima pendapat orang lain, dinamakan nurturant effect. (Mujiono; 2000: 10).

Salah satu cerminan keberhasilan belajarmengajar adalah hasil belajar siswa yang dicapai oleh siswa di sekolah tersebut. Dengan demikian hasil belajar siswa pada suatu mata pelajaran tertentu merupakan salah satu indikator kualitas pendidikan di sekolah yang bersangkutan.

Peningkatan kualitas ilmu pendidikan pada jenjang pendidikan dasar dan menengah dilakukan pada semua kelompok mata pelajaran yang tertuang dalam standar isi. Akan tetapi Sekolah Menengah Kejuruan mempunyai kekhususan dalam Standar Isi (SI) dan Standar Kompetensi Kelulusan (SKL) mata pelajaran produktif. Hal ini menjadikan pertimbangan bahwa KTSP di SMK harus mengacu pula pada Standar Kompetensi Kerja Nasional Indonesia (SKKNI), sementara belum semua program keahlian memiliki SKKNI. (Pusat Kurikulum Badan Penelitian dan Pengembangan Departemen Pendidikan Nasional; 2007: 5).
Ilmu Bangunan Gedung (IBG) merupakan salah satu mata pelajaran yang diajarkan di kelas X Teknik Kontruksi Batu dan Beton. Ada beberapa kendala yang dihadapi dalam melaksanakan proses belajar-mengajar mata pelajaran ini. Beberapa di antaranya adalah pembelajaran masih konvensional dan pelatihan dilakukan dengan strategi sajian presentasi yang monoton dan tidak memberikan kesempatan kepada siswa untuk mengartikulasikan tentang hal yang dipelajari dan cenderung membosankan. Oleh karena itu diperlukan suatu tindakan untuk memperbaiki proses pembelajaran dan diharapkan terjadinya peningkatan hasil belajar. Salah satu model pembelajaran yang sesuai dengan kurikulum 2013 yang dikembangkan sekarang adalah Pembelajaran Berbasis Masalah. Pengajaran ini menggunakan masalah dunia nyata sebagai suatu konteks belajar bagi siswa tentang cara berfikir kritis dan ketrampilan pemecahan masalah.

SMK Negeri 2 Binjai merupakan salah satu SMK favorit di kota Binjai, Berdasarkan observasi awal yang dilakukan peneliti, 3\% siswa pandai menunjukkan keaktifan dan peran sertanya, $40 \%$ siswa kurang semangat, $20 \%$ siswa merasa bosan dan berbicara dengan teman.

Hasi belajar ilmu bangunan gedung siswa kelas X pada tahun 2010-2011 dibawah nilai 6,9 mencapai 57.6\%, tahun 2011-2012 di bawah nilai 6,9 mencapai $58.8 \%$, pada tahun 2012-2013 di bawah nilai 6,9 mencapai $62,9 \%$, sehingga hasil belajar siswa masih belum memenuhi standart kelulusan minimum.

\section{Metodologi Penelitian}

Penelitian tindakan kelas ini dilaksanakan di SMK Negeri 2 Binjai Program Keahlian Teknik Kontruksi Batu Beton pada mata pelajaran Ilmu Bangunan Gedung. Observasi dan penelitian ini dilaksanakan pada Tahun Ajaran 2014/2015, observasi dilakukan pada bulan Februari 2014 dan Penelitian dilakukan pada bulan Desember 2014 sampai dengan selesai.

Subjek penelitian ini adalah siswa kelas $X$ Program Keahlian Teknik Kontruksi Batu dan Beton Tahun Pelajaran 2014/2015, dan objek dari penelitian ini adalah meningkatkan 


\section{Penerapan Model Pembelajaran Berbasis Masalah Untuk Meningkatkan Keaktifan dan Hasil Belajar IImu Bangunan Gedung Pada siswa Kelas X Teknik Konstrruksi Batu dan Beton SMK Negeri 2 Binjai Tahun Ajaran 2014/2015}

keaktifan dan hasil belajar siswa. Dengan jumlah sebanyak 1 kelas yang terdiri dari 31orang.

Penelitian tindakan kelas ini dilaksanakan melalui dua siklus dan masing-masing siklus terdiri dari empat tindakan yaitu (1) perencanaan, (2) pelaksanaan, (3) Pengamatan dan (4) refleksi. Adapun langkah-langkah yang akan dilakukan dalam proses penelitian ini adalah :

a. Melakukan observasi lingkungan sekolah, guru yang sedang mengajar dan siswa yang menjadi objek penelitian.

b. Melakukan diskusi dengan PKS I dan bekerjasama dengan guru mata pelajaran ilmu bangunan gedung untuk menganalisis kurikulum tentang penerapan model Pembelajaran Berbasis Masalah dalam belajar.

c. Melakukan proses pembelajaran dengan menggunakan model Pembelajaran Berbasis Masalah dimana aktivitas belajar siswa diamati pada saat siswa berdiskusi, dengan menjelaskan terlebih dahulu cara kerja model Pembelajaran Berbasis Masalah kepada siswa.

d. Setelah proses pembelajaran dengan menggunakan model Pembelajaran Berbasis Masalah selesai maka siswa diberikan tes dengan tujuan untuk mengetahui apakah hasil belajar siswa mengalami peningkatan.

e. Melakukan refleksi dengan melihat hasil tes belajar siswa yang dijadikan sebagai dasar untuk melaksanakan siklus berikutnya.

Untuk mengetahui tingkat keaktifan belajar siswa, peneliti membuat lembar observasi keaktifan siswa yang akan digunakan observer sebanyak dua kali pada setiap siklusnya yaitu pada siklus I dan siklus II.

Pada setiap siklusnya guru (observer) menilai keaktifan siswa dengan menggunakan lembar observasi keaktifan, untuk mengetahui peningkatan keaktifan siswa pada saat dilakukan penerapan model pembelajaran berbasis masalah.

Berdasarkan data yang diperoleh dari hasil penelitian dengan jumlah responden 31 orang siswa, dapat diketahui bahwa perolehan nilai keaktifan belajar siswa meningkat dari siklus I ke siklus II. Berikut ini adalah hasil observasi aktivitas siswa kelas kelas $\mathrm{X}$ program keahlian
Teknik Kontruksi Batu dan Beton di SMK Negeri 2 Binjai.

Tabel 1. Perolehan Skor Keaktifan Belajar Siswa

\begin{tabular}{|c|c|c|c|c|c|c|c|c|}
\hline \multirow{7}{*}{$\begin{array}{l}\text { Si } \\
\text { kl } \\
\text { us }\end{array}$} & \multicolumn{2}{|c|}{$\begin{array}{c}\text { Kurang } \\
\text { Aktif }\end{array}$} & \multicolumn{2}{|c|}{$\begin{array}{c}\text { Cukup } \\
\text { Aktif }\end{array}$} & \multicolumn{2}{|c|}{ Aktif } & \multicolumn{2}{|c|}{$\begin{array}{c}\text { Sangat } \\
\text { Aktif }\end{array}$} \\
\hline & $\mathrm{Jl}$ & & $\mathrm{Jl}$ & & $\mathrm{Jl}$ & & $\mathrm{Jl}$ & \\
\hline & $\mathrm{h}$ & & $\mathrm{h}$ & & $\mathrm{h}$ & & $\mathrm{h}$ & \\
\hline & $\mathrm{Si}$ & $\%$ & si & $\%$ & Si & \% & $\mathrm{Si}$ & o \\
\hline & $\mathrm{s}$ & 10 & $\mathrm{~s}$ & 10 & S & 10 & $\mathrm{~s}$ & 70 \\
\hline & $\mathrm{W}$ & & W & & W & & W & \\
\hline & $\mathrm{a}$ & & $\mathrm{a}$ & & $\mathrm{a}$ & & $\mathrm{a}$ & \\
\hline I & 4 & $\begin{array}{c}12, \\
90\end{array}$ & 14 & $\begin{array}{l}45 \\
19\end{array}$ & 13 & $\begin{array}{l}41, \\
94\end{array}$ & - & - \\
\hline II & - & - & 4 & $\begin{array}{l}12, \\
90\end{array}$ & 17 & $\begin{array}{l}54, \\
84\end{array}$ & 10 & $\begin{array}{l}32, \\
26\end{array}$ \\
\hline
\end{tabular}

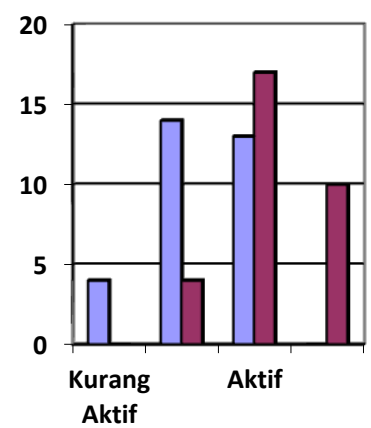

口Siklus

口Siklus II

Gambar 1. Grafik Keaktifan Belajar Siswa

Data hasil penelitian terdiri dari hasil pretest, dan nilai postest pada siklus I dan siklus II. Hasil pretest berfungsi untuk melihat kemampuan awal siswa, sedangkan postest siklus I di fungsi untuk melihat kemampuan akhir siswa setelah diterapkan model pembelajaran berbasis masalah pada mata pelajaran Ilmu Bangunan Gedung. Kemudian dilakukan siklus ke II untuk lebih meningkatkan kemampuan siswa, dan diberikan posttest siklus II untuk melihat peningkatan siswa setelah dilakukan penerapan kolaborasi model pembelajaran berbasis masalah pada mata pelajaran Ilmu Bangunan Gedung di siklus II.

Adapun hasil perolehan nilai dan skor siswa pada saat pretest dan posttest adalah sebagai berikut:

Tabel 2. Rata-rata Hasil Belajar Siswa

\begin{tabular}{cccccc}
\hline \multirow{2}{*}{$\begin{array}{c}\text { Jenis } \\
\text { Tes }\end{array}$} & \multicolumn{2}{c}{ Tuntas } & \multicolumn{2}{c}{ Tidak Tuntas } & Rata- \\
\cline { 2 - 4 } & siswa & $\%$ & JLh & $\%$ & rata \\
\hline
\end{tabular}




\begin{tabular}{cccccc}
\hline Pretest & 8 & $25,81 \%$ & 23 & $74,19 \%$ & $58,94 \%$ \\
\hline $\begin{array}{c}\text { Postest } \\
\text { siklus I }\end{array}$ & 19 & $61,29 \%$ & 12 & $38,71 \%$ & $66,61 \%$ \\
\hline $\begin{array}{c}\text { Postest } \\
\text { siklus } \\
\text { II }\end{array}$ & 27 & $87,10 \%$ & 4 & $12,90 \%$ & $76,10 \%$ \\
\hline
\end{tabular}

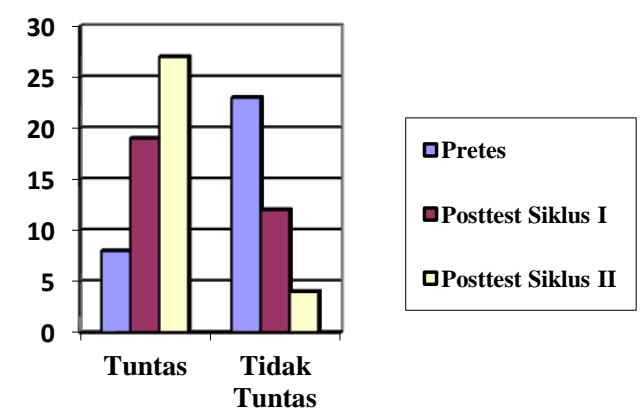

Gambar 2. Grafik Rata-rata Hasil Belajar Siswa

Setelah dilakukan pembelajaran pada siklus II dan diadakan refleksi dan evaluasi, diperoleh hasil belajar siswa dengan peningkatan dari siklus I ke siklus II sebesar $25,81 \%$ dengan jumlah siswa yang tuntas belajar pada siklus II sebesar $87,10 \%$. Hal ini menunjukkan bahwa siklus II sudah mencapai kriteria ketuntasan secara klasikal yaitu $85 \%$ siswa harus memperoleh nilai $\geq 70$. Demikian juga aktivitas siswa dalam proses belajar mengajar semakin meningkat dimana 4 orang $(12,90 \%)$ siswa untuk kriteria cukup, 17 orang $(54,84 \%)$ siswa untuk kriteria aktif, dan 10 orang (32,26\%) siswa untuk kriteria sangat aktif. Hal ini juga sekaligus menandakan tidak perlu dilakukan siklus selanjutnya.

Peningkatan ini menunjukkan bahwa dengan menggunakan model pembelajaran berbasis masalah siswa mampu memahami materi dengan baik sehingga dapat meningkatkan keaktifan dan hasil belajar Ilmu Bangunan Gedung kelas X program keahlian Teknik Kontruksi Batu dan Beton di SMK Negeri 2Binjai.

\section{Kesimpulan, Implikasi dan Saran 3.1 Kesimpulan}

Berdasarkan hasil penelitian tindakan kelas yang telah dilakukan, maka dapat dibuat kesimpulan sebagai berikut:

a. Rata-rata hasil Keaktifan belajar siswa setelah dilaksanakan Pembelajaran Berbasis
Masalah mengalami peningkatan keaktifan belajar siswa yaitu dari siklus I dengan ratarata $63 \%$ meningkat menjadi $81 \%$ pada siklus II. Oleh karena itu, penerapan Pembelajaran Berbasis Masalah dapat meningkatkan keaktifan belajar siswa pada mata pelajaran Ilmu Bangunan Gedung Kelas X Program Keahlian Konstruksi Batu dan Beton Sekolah Menengah Kejuruan Negeri 2 Binjai Tahun Ajaran 2014/2015.

b. Rata-rata Hasil belajar siswa setelah diterapkan Model Pembelajaran Berbasis Masalah mengalami peningkatan, yaitu dari siklus I $66,61 \%$ dan pada siklus II 76,10\%. Dengan persentase ketuntasan pada siklus I sebesar $61,29 \%$ dan pada siklus II sebesar $87,10 \%$ sehingga Model Pembelajaran Berbasis Masalah dapat meningkatkan dan mencapai nilai ketuntasan yang telah di tetapkan pihak sekolah SMK Negeri 2 Binjai.

\subsection{Implikasi}

Berdasarkan hasil penelitian dan simpulan penelitian diberikan implikasi sebagai berikut:

a. Dengan telah diterimanya penerapan metode Pembelajaran Berbasis Masalah dalam meningkatkan keaktifan siswa, Maka jika digunakan metode Pembelajaran Berbasis Masalah dapat meningkatkan keaktifan siswa dalam pembelajaran Ilmu Bangunan Gedung.

b. Dengan telah diterimanya penerapan metode Pembelajaran Berbasis Masalah dalam meningkatkan hasil belajar siswa, Maka jika digunakan metode Pembelajaran Berbasis Masalah dapat meningkatkan hasil belajar siswa dalam pembelajaran Ilmu Bangunan Gedung.

\subsection{Saran}

Berdasarkan kesimpulan di atas, saran yang dapat diberikan kepada pelaksanaan penerapan Pembelajaran Berbasis Masalah adalah:

a. Diharapkan kepada kepala sekolah dapat membuat kebijakan sehingga guru dapat menerapkan metode Pembelajaran Berbasis Masalah agar dapat memberikan perubahan yang baik untuk kegiatan belajar mengajar di kelas dalam mata pelajaran Ilmu Bangunan Gedung kelas X SMK negeri 2 binjai.

b. Diharapkan kepada guru mata pelajaran Ilmu bangunan gedung agar dapat 


\section{Penerapan Model Pembelajaran Berbasis Masalah Untuk Meningkatkan Keaktifan dan Hasil Belajar IImu Bangunan Gedung Pada siswa Kelas X Teknik Konstrruksi Batu dan Beton SMK Negeri 2 Binjai Tahun Ajaran 2014/2015}

menerapkan Pembelajaran Pembelajaran Berbasis Masalah untuk meningkatkan keaktifan dan hasil belajar siswa.

c. Diharapkan kepada siswa agar dapat memahami metode ini agar keaktifan dan hasil belajar siswa dapat meningkat dan siswa harus lebih cerdas dan serius dalam memahami mata pelajaran Ilmu Bangunan Gedung.

d. Bagi penelitian lain yang ingin meneliti pada judul penelitian yang sama hendaknya memperhatikan alokasi waktu yang digunakan pada saat pembagian kelompok di dalam kelas dan sebaiknya kelompok sudah dibentuk terlebih dahulu yang sudah didiskusikan oleh guru sebelum melakukan penerapan model. Agar memperoleh hasil yang lebih baik diharapkan melakukan penelitian pada sekolah yang berbeda dengan objek penelitian yang berbeda pula sehingga dapat mengetahui sejauh mana model ini dapat memberi pengaruh terhadap keaktifan dan hasil.

\section{Daftar Pustaka}

Abbas, Nurhayanti. 2000. Pengembangan Perangkat Pembelajaran Matematika Berorientasi Model Pembelajaran Berbasis Masalah (Problem Based Instruction). Program Studi Pendidikan Matematika Pasca Sarjana.

Surabaya: UNESA.

Ahmad dan Ir.Rosman. 2007. Bahan Bangunan sebagai Dasar Pengetahuan.

Bangun. Jakarta : Cipta Pustaka

Arikunto, dkk . 2008. Penelitian Tindakan Kelas. Jakarta : Bumi Aksara.

dkk . 2002. Penelitian Tindakan Kelas. Jakarta : Bumi Aksara., Suharsimin. 2008. Dasar-Dasar Evaluasi Pendidikan. Jakarta : Bumi Aksara.

Diraatmaja, 2005. Membangun, Ilmu Bangunan. Jakarta: Erlangga Departemen Pendidikan Nasional, direktorat pendidikan menengah kejuruan Kurikulum Edisi 1999, Jakarta.

Dimyati, 2009. Belajar dan Pembelajaran Jakarta :PT Rineka Cipta Ibrahim, Muslim dan Nur. 2000. Pembelajaran Berbasis Masalah. Surabaya:UNESA.2002.
Pembelajaran Berbasis Masalah. Surabaya:UNESA.

Lepinski ,2005. Pembelajaran Berbasis Masalah http://tep.um.ac.id/berita-223- berbasismasalah---problembased learning.html. (diakses 8 April 2014).

Mujiono. 2000. Proses Belajar Mengajar.

Bandung: Remaja Rosdakarya.

Nurhadi. 2003. Kurikulum 2002. Jakarta :

Grasindo.

Nursalam,2003,http:// digilib.unimus.ac. id/files/di sk1/111 gdl-ubaidillah-55163babiip-f.pdf.

Nuryenti, Diah Eko. 2002. Model Pembelajaran Berbasis Masalah Untuk Mengembangkan Kecakapan Matematika Siswa Sekolah Dasar (SD) Kelas III Sebagai Implementasi Kurikulum Berbasis Kompetensi (KBK).

Sardiman. 2008. Interaksi dan Motivasi Belajar Mengajar. Jakarta: Grafindo Persada.

Setiawan, Pujo L. 2007. Ilmu konstruksi struktur bangunan. Yogyakarta.

Sudjana Nana. 2004. Penilaian Hasil Proses Belajar Mengajar. Bandung: PT. Remaja Rosdakarya. Skripsi SI Pendidikan Matematika UNNES

Wardani, Igak. 2007. Penelitian Tindakan Kelas. Jakarta : Departemen Pendidikan Nasional Universitas Terbuka.

W.S. Winkel. 2005. Psikologi Pengajaran. Yogyakarta : Media Cipta . 2009. Pedoman Penulisan Skripsi FKIP UNS. Surakarta : UNS Pers. 